\title{
Insulin Oedema in Newly Diagnosed Type 1 Diabetes Mellitus
}

\author{
Veysel Nijat Baş, Semra Çetinkaya, Sebahat Yılmaz Ağladıoğlu, Havva Nur Peltek Kendirci, \\ Hatice Bilgili, Nurdan Yıldırım, Zehra Aycan \\ Dr. Sami Ulus Women Health, Children's Education and Research Hospital Section of Pediatric Endocrinology, Ankara, Turkey
}

\begin{abstract}
Despite the essential role of insulin in the management of patients with insulin deficiency, insulin use can lead to adverse effects such as hypoglycaemia and weight gain. Rarely, crucial fluid retention can occur with insulin therapy, resulting in an oedematous condition. Peripheral or generalised oedema is an extremely rare complication of insulin therapy in the absence of heart, liver or renal involvement. It has been reported in newly diagnosed type 1 diabetes, in poorly controlled type 2 diabetes following the initiation of insulin therapy, and in underweight patients on large doses of insulin. The oedema occurs shortly after the initiation of intensive insulin therapy. We describe two adolescent girls with newly diagnosed type 1 diabetes, who presented with oedema of the lower extremities approximately one week after the initiation of insulin treatment; other causes of oedema were excluded. Spontaneous recovery was observed in both patients.

Key words: Type 1 diabetes, insulin oedema, adolescence
\end{abstract}

Received: 30.9 .2009

Accepted: 05.11.2009

\section{Introduction}

Insulin is essential in type 1 diabetes, including the emergency treatment of ketoacidosis. It may also be needed in type 2 diabetes for intercurrent events like surgery, infections, serious illness, trauma, pregnancy and for emergency treatment of hiperkalemia (1). While insulin has an essential role in the management of patients with insulin deficiency, its clinical use may lead to adverse effects such as hypoglycaemia and weight gain. The reason of weight gain associated with insulin treatment is poorly understood and has been attributed to increased vascular permeability and shifted renal sodium handling in addition to the anabolic effect of insulin. Rarely, crucial fluid retention can occur with insulin therapy. Peripheral or generalised oedema is an extraordinary complication of insulin therapy in the absence of heart, liver or renal involvement. It has been reported in newly diagnosed type 1 diabetes, in poorly controlled type 2 diabetes following the initiation of insulin therapy, and in underweight patients on large doses of insulin. The oedematous state develops briefly after the initiation of intensive insulin therapy (2-4). The pathophysiology remains vague, although the condition was first described as early as 1928 (3). Reported cases of insulin-induced oedema in childhood and adolescence are scarce $(1,5)$. The first pediatric report dates back to 1979 (6), and ten more cases have been reported since then (6-9). Herein we describe insulin oedema in two adolescent girls with newly diagnosed diabetes.

\section{Address for Correspondence}

Veysel Nijat Baş, Dr. Sami Ulus Women Health, Children's Education and Research Hospital, Clinics of Pediatric Endocrinology, Ankara, Turkey Phone: +90 3123056508 Fax: +903123170353 E-mail: veyselbas@yahoo.com

(c) Journal of Clinical Research in Pediatric Endocrinology, Published by Galenos Publishing. 


\section{Case 1}

A 14-year-old girl was admitted with a 1-month history of polyuria and polydipsia. A recent weight loss of $5 \mathrm{~kg}$ was also mentioned. No family history of diabetes was reported. Physical examination at the time of admission revealed a temperature of $36.7^{\circ} \mathrm{C}$, a pulse of 66 beats per minute, a respiratory rate of 24 per minute, and a blood pressure of $110 / 70 \mathrm{~mm} / \mathrm{Hg}$. The patient's height was $161 \mathrm{~cm}(-0.01 \mathrm{SDS})$ and her weight was $40 \mathrm{~kg}(-2.85$ SDS). Calculated body mass index was $15.6 \mathrm{~kg} / \mathrm{m}^{2} \quad(-2,7$ SDS). Careful history excluded anorexia nervosa as a contributing condition to her weight loss. She was at pubertal Tanner stage 5. Laboratory investigations revealed a blood glucose level of $363 \mathrm{mg} / \mathrm{dL}$, ketonuria with acidosis, an arterial blood pH of 7.2 and an elevated glycosylated haemoglobin A1c concentration of $12.1 \%$. The patient was initially treated with an intravenous infusion of insulin and $2 / 3$ isotonic saline in 5\% dextrose. Mild bilateral pitting ankle oedema and discoloration of the skin developed over the ankles. The oedema deteriorated on the fourth day, after the initiation of regular insulin administered subcutaneously, at a dose of 1.2 units $/ \mathrm{kg} /$ day (Figure 1). No evidence of heart, liver or kidney dysfunction was noted. Serum albumin levels decreased from 3.5 to $3.2 \mathrm{~g} / \mathrm{dL}$, without proteinuria. Chest X-ray and abdominal ultrasound findings were normal. Doppler ultrasound findings of the lower leg arteries and veins were normal. Ten days later the oedema had completely resolved without any specific treatment.

\section{Case 2}

An 11-year-old girl was admitted with an 8-month history of polyuria, polydipsia and a recent weight loss of $7 \mathrm{~kg}$. No family history of diabetes was reported. Physical examination at the time of admission revealed a temperature of $37^{\circ} \mathrm{C}$, a pulse rate of 96 beats per minute, a respiratory rate of 28 per minute, and a blood pressure of 100/65 mm/Hg. Her height was $147 \mathrm{~cm}(-0.31$ SDS) and her weight $30 \mathrm{~kg}(-1.75 \mathrm{SDS})$. Calculated body mass index was 13.8 (-1.9 SDS) kg/m². Pubertal stage was evaluated as Tanner stage 3. Physical examination was normal except for clinical signs of mild dehydration. Laboratory investigations revealed a blood glucose level of $453 \mathrm{mg} / \mathrm{dL}$, ketonuria with acidosis, an arterial blood $\mathrm{pH}$ of 7.1 and an elevated glycosylated haemoglobin A1c concentration of $13.9 \%$. The patient was treated with $2 / 3$ isotonic saline in $\% 5$ dexstrose and intravenous insulin infusion. On the fifth day of regular insulin administration, a non-tender, pitting oedema without skin discoloration developed over the ankles
(Figure 2). No evidence of heart, liver or renal dysfunction was noted. Serum albumin levels remained stable. Chest X-ray and abdominal ultrasound findings were normal. Doppler ultrasound findings of the lower leg arteries and veins were normal. Seven days later the oedema disappeared completely without any treatment.

Further investigations revealed positive anti-GAD (glutamic acid decarboxylase) and anti-islet cell antibodies in both patients.

\section{Discussion}

Insulin oedema is presumably an underreported physical finding. The severity of the peripheral oedema is variable, most cases being mild. Oedema has been accepted as an uncommon complication occurring after initiating or intensifying the insulin treatment (3). Leifer (2), in 1928, proposed that rapid retention of tissue fluid secondary to glycogen deposition was responsible for the pathophysiology of insulin oedema. In subsequent years, the direct antinatriuretic effect of insulin on the kidney was recognised and insulin oedema was attributed to alterations in renal electrolyte transport (10). Insulin-induced oedema was found to occur equally in adult men and women, but a clear female predominance was noted in younger ages $(3,6)$. Both our patients were also females. In addition, the reported pediatric cases were all recently diagnosed patients with type 1 diabetes, similar to our patients. Intensive fluid resuscitation in an insulin-deficient catabolic state may lead to extravasation of fluid to the subcutaneous tissue, resulting in peripheral oedema. This may be exacerbated by the increased capillary permeability associated with chronic hyperglycaemia (11). Renal tubular sodium reabsorption is enhanced by insulin therapy via stimulating the $\mathrm{Na}^{+} / \mathrm{K}^{+}$-ATPase as well as the expression of $\mathrm{Na}^{+} / \mathrm{H}^{+}$ exchanger 3 in the proximal tubule $(12,13)$. Transient inappropriate hyperaldosteronism has also been suggested to contribute to the fluid retention (12). In our cases, normal plasma aldosterone/renin ratio was accompanied by significant natriuresis, leading to recovery of the abnormal sodium handling in the renal tubules. Interestingly, many of the described patients with insulin-induced oedema were substantially underweight, with the most dramatic presentation occurring in the underweight patients (14), a finding similar to our two cases. Our patients were thin adolescents, who had considerable weight loss before admission. In several patients it was reported that loss of albumin from the circulation due to increased transcapillary leakage probably contributed to the formation of oedema and the decreased serum albumin, but was not severe 


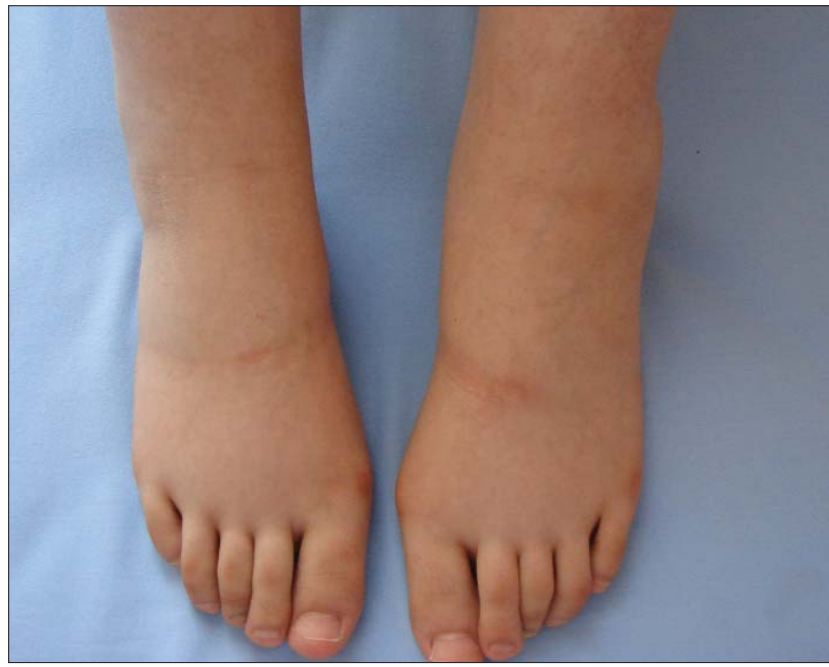

Figure 1. Lower extremity oedema 4 days after the initiation of insulin therapy in Case 1

enough to account for the magnitude of oedema (15). Similar findings were true for our patients. Cases with normal serum albumin have also been reported. Clinically, insulin oedema may present with a spectrum of severity from mild pedal oedema to frank anasarca. Pleural effusions have uncommonly been reported, although some of these patients were elderly and may have had pre-existing cardiac disease. Rarely, the oedema extended from peripheral tissues to serosal cavities with ascites and cardiac failure $(14,16,17)$.

In patients with insulin oedema, fluid and salt restriction should be implemented and this may be all that is necessary. Diuretic therapy may be indicated in more severe decompensated cases. Administration of an aldosterone antagonist such as spironolactone may be considered from a pathophysiological point of view in the presence of inappropriate hyperaldosteronism; however, the treatment with other diuretics appears to be also effective ( $\hat{i} 2)$. In most instances no therapy is needed and spontaneous recovery is noted, as was the case in our patients.

\section{References}

1. Alemzadeh R, Wyatt D. Diabetes mellitus. In: Behrman RE, Kliegman RM, Jenson HB (ed) Nelson Textbook of Pediatrics $17^{\text {th }}$ Edition. Saunders, Philadelphia 2004. pp. 1947-72.

2. Leifer A. A case of insulin oedema. JAMA 1928;90:610-611. [Abstract] / [Full Text] / [PDF]

3. Hopkins DF, Cotton SJ, Williams G. Effective treatment of insulin-induced edema using ephedrine. Diabetes Care 1993;16:1026-1028. [Abstract]

4. Juliusson PB, Bjerknes R, Sovik O, Kvistad PH. Generalised edema following insulin treatment of newly diagnosed diabetes mellitus. Tidsskr Nor Laegeforen 2001;121:919-920. [Abstract] / [Full Text]

5. Sperling MA. Pediatric Endocrinology. Second Edition Philedelphia: WB Saunders Company 2002;325-53.

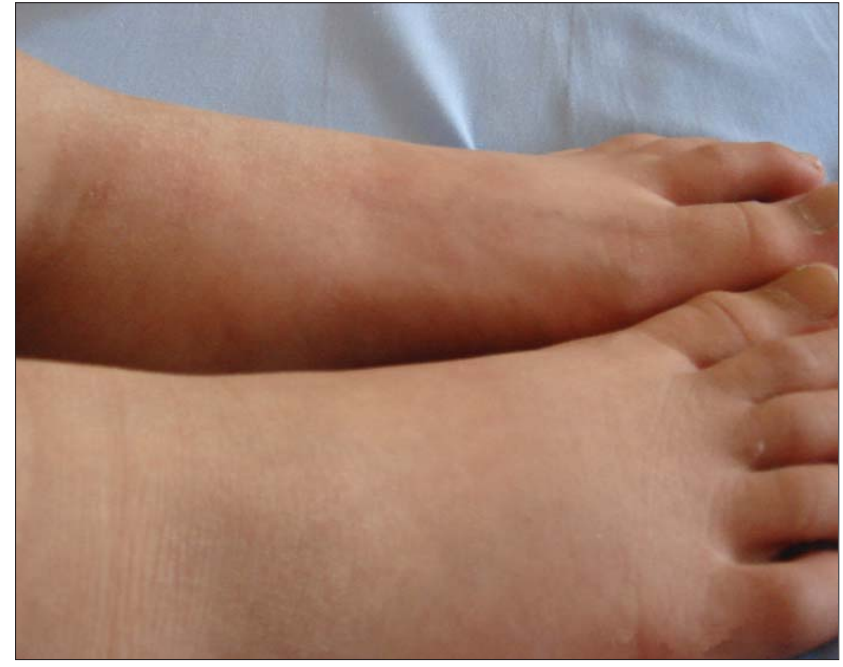

Figure 2. Lower extremity oedema 5 days after the initiation of insulin therapy in Case 2

6. Lawrence JR, Dunnigan MG. Diabetic (insulin) oedema. Br Med J 1979;2:445. [Abstract] / [Full Text]

7. Mamoulakis D, Bitsori M, Galanakis E, Raissaki M, Kalmanti M. Insulin-induced oedema in children and adolescents. J Paediatr Child Health 2006;42:655-657. [Abstract] / [Full Text] / [PDF]

8. Sharon M, Cassorla FG, Rose SR, Loriaux DL. Edema associated with improved glycemic control in an adolescent with type 1 diabetes. J Pediatr 1987;111:403-404. [Abstract] / [PDF]

9. Lwo FS, Lee YJ. Insulin edema in a diabetic child. J Formos Med Assoc 1995;94:509-511. [Abstract]

10. DeFronzo RA, Cooke CR, Andres R, Faloona GR, Davis PJ. The effect of insulin on renal handling of sodium, potassium, calcium and phosphate in man. J Clin Invest 1975;55:845-855. [Abstract] / [Full Text] / [PDF]

11. O'Hare JA, Ferriss JB, Twomey B, O'Sullivan DJ. Poor metabolic control, hypertension and microangiopathy independently increase the transcapillary escape rate of albumin in diabetes. Diabetologia 1983;25:260-263. [Abstract] / [PDF]

12. Kalambokis G, Tsatsoulis A, Economou G, Tsianos EV. A case of insulin edema with inappropriate hyperaldosteronism. J Endocrinol Invest 2004;27:957-960. [Abstract]

13. Klisic J, Hu MC, Nief V, Reyes L, Fuster D, Moe OW, Ambuhl PM. Insulin activates $\mathrm{Na}(+) / \mathrm{H}(+)$ exchanger 3: biphasic response and glucocorticoid dependence. Am J Physiol Renal Physiol 2002;283:F532-539. [Abstract] / [Full Text] / [PDF]

14. Shaper AG. The insulin-oedema syndrome in African diabetic subjects. Trans R Soc Trop Med Hyg 1966;60:519-525. [Full Text]

15. Wheatly T, Edwards OM. Insulin oedema and its clinical significance: metabolic studies in three cases. Diabet Med 1985;2:400-404. [Abstract] / [PDF]

16. Sheehan JP, Sisam DA, Schumacher OP. Insulin-induced cardiac failure. Am J Med 1985;79:147-148. [Abstract] / [PDF]

17. Lee $\mathrm{P}$, Kinsella J, Borkman M, Carter J. Bilateral pleural effusions, ascites, and facial and peripheral oedema in a 19-year-old woman 2 weeks following commencement of insulin lispro and detemir--an unusual presentation of insulin oedema. Diabet Med 2007;24:1282-1285. [Abstract] / [Full Text] / [PDF] 